\title{
LISTS OF TABLES AND FIGURES
}

\author{
List of Tables
}

1.1 Some of the bazaar medicines used by the EEIC Madras establishment.

5.1 Population of the West Indies.

\section{List of Figures}

1.1 Seller of medicines, eighteenth-century India.

2.1 Draught of Port Royal and Kingston harbours, showing New Greenwich.

3.1 'Plan of Fort St George and the city of Madras'.

6.1 The Bath Hot Spring, Jamaica. 